\title{
Comparison of Defensive Enzyme Activities in the Leaves of Seven Oriental Lily Hybrids after Inoculation with Botrytis elliptica
}

\author{
Guangxin Liu \\ College of Biology and the Environment, Co-Innovation Center for the Sustainable Forestry in \\ Southern China, Nanjing Forestry University, Nanjing 210037, China \\ Xiaoqian Su, Lingling Guan, and Fengrong $\mathrm{Hu}^{\mathbf{1}}$ \\ College of Landscape Architecture, Nanjing Forestry University, Nanjing 210037, China
}

\begin{abstract}
AdDitional INDEX words. Lilium, leaf blight, superoxide dismutase, catalase, phenylalanine ammonia-lyase, peroxidase
Abstract. Plant resistance characteristics are closely related to changes in the activities of self-defense enzymes after infection. Despite significant differences in the resistance of different lily (Lilium sp.) cultivars to leaf blight (Botrytis elliptica), few studies of their resistance physiology exist. This study explored changes in the resistance-related enzyme activity of several lily cultivars after leaf blight inoculation. Seven oriental lily cultivars (Lilium hybrids) with obvious differences in resistance were used as experimental materials. After inoculation with $B$. elliptica, the activities of four defense enzymes, superoxide dismutase (SOD), catalase (CAT), phenylalanine ammonia-lyase (PAL), and peroxidase (POD), were determined according to the light absorption values at different wavelengths after their reactions. The results showed that the activities of SOD and CAT differed between the highly resistant and highly susceptible hybrids. Before inoculation, SOD activity was relatively low in all cultivars. However, after inoculation, the SOD activity increased sharply in the resistant cultivars. In the moderately resistant cultivars, the SOD activity did not change drastically. In the susceptible cultivars, the SOD activity initially showed slight increases or decreases and then increased. CAT activity showed reactions similar to those of SOD. Some changes in PAL and POD activity occurred after inoculation, but no significant correlations were present between these trends and resistance characteristics. In addition, no significant changes in enzyme activities were found in the control plants of the seven cultivars during the testing period. Overall, the resistance of Lilium oriental hybrids to B. elliptica is related to SOD and CAT activity but does not show much of a relationship with PAL and POD activity. Studying the physiological metabolic pathways of SOD and CAT appears to be an important direction in research to elucidate resistance to B. elliptica in Lilium oriental hybrids.
\end{abstract}

During normal plant growth and development, active oxygen production and elimination maintain a dynamic equilibrium in the cells. However, when the plant is infected by disease, this equilibrium state will be disrupted and the production of active oxygen in cells will exceed its removal. This imbalance results in the accumulation of reactive oxygen in plant cells, which can damage the membrane system, especially the mitochondrial and chloroplast membranes (Song, 2016).

To protect plant cells from these harmful products, some enzymes function to clear free radicals and reactive oxygen. When plants are infected by pathogens, some enzyme activities are enhanced and others are reduced. These changes in enzyme activity affect various physiological and biochemical metabolic pathways in plants, consequently affecting the growth and development of plants and pathogens (Espinosa-Leal et al., 2018). Most reports have focused on enzymes such as phenylalanine ammonia-lyase, peroxidase, superoxide dismutase, and catalase because these enzymes participate in not only phenol metabolism but also the formation and accumulation of

Received for publication 19 July 2018. Accepted for publication 8 Nov. 2018. This study was supported by Jiangsu University Brand Specialization Project Support Project (PPZY2015A063) and A Project Funded by the Priority Academic Program Development of JiangSu Higher Education Institution (PAPD), China.

The funders had no roles in the design, analysis, writing, or submission of this work.

${ }^{1}$ Corresponding author. E-mail: hufengren@163.com bioresistant substances such as lignin and phytoalexin (Ighodaro and Akinloye, 2017). Therefore, they are important to the study of the physiological and biochemical mechanisms of plant disease resistance. For example, superoxide dismutase (SOD) is one of the most important scavenging enzymes; it catalyzes the dismutation of superoxide radicals to the active oxygen species hydrogen peroxide (Ehsani-Moghaddam et al., 2006; Hameed and Iqbal 2014). Catalase (CAT) is an oxygenscavenging enzyme that has a specific peroxidative role protecting cells from the toxic effects of its substrate $\left(\mathrm{H}_{2} \mathrm{O}_{2}\right)$, which is otherwise lethal, during development (Choodamani et al., 2009; Hameed and Iqbal, 2014; Patel et al., 2011). Phenylalanine ammonia-lyase (PAL) is the primary enzyme in phenylpropanoid metabolism; it has a significant role in the synthesis of several defense-related secondary compounds such as phenols and lignin (Hemm et al., 2004; Tahsili et al., 2014). The inhibition of PAL affects subsequent biosynthetic pathways involving phenolic compounds (Jayaraj et al., 2010). To determine the correlated physiological and biochemical indexes for evaluating the resistance of eggplant (Solanum melongena) to verticillium wilt (Verticillium dahliae), Zhou (2012) investigated the activities of defense-related enzymes, including PAL, peroxidase (POD), and CAT. They found that resistance was significantly positively correlated with both PAL activity and POD activity. However, no correlation between resistance and CAT activity was detected. Siddique et al. (2014) investigated the activities of PAL, POD, CAT, 
Table 1. Superoxide dismutase (SOD), peroxidase (POD), catalase (CAT), and phenylalanine ammonia-lyase (PAL) activities of the control (uninoculated) plants in each of seven Lilium oriental cultivars.

\begin{tabular}{|c|c|c|c|c|c|c|}
\hline \multirow[b]{3}{*}{ Cultivar } & \multirow[b]{3}{*}{ Index } & \multicolumn{5}{|c|}{ Detection time } \\
\hline & & Day 1 & Day 3 & Day 5 & Day 7 & Day 9 \\
\hline & & \multicolumn{5}{|c|}{ Enzyme activity (U/g) } \\
\hline \multirow{4}{*}{ Constanta } & SOD & $82.158^{z}$ & 79.526 & 83.575 & 80.162 & 84.473 \\
\hline & POD & 8.971 & 9.158 & 8.765 & 8.847 & 9.097 \\
\hline & CAT & 1.375 & 1.291 & 1.336 & 1.451 & 1.354 \\
\hline & PAL & 36.972 & 37.257 & 34.944 & 38.256 & 35.321 \\
\hline \multirow[t]{4}{*}{ Siberia } & SOD & 30.293 & 33.213 & 31.561 & 28.341 & 27.684 \\
\hline & POD & 4.635 & 4.379 & 4.891 & 4.645 & 4.967 \\
\hline & CAT & 1.063 & 0.987 & 1.102 & 0.994 & 1.124 \\
\hline & PAL & 34.472 & 36.457 & 32.987 & 35.214 & 35.179 \\
\hline \multirow[t]{4}{*}{ Sorbonne } & SOD & 75.732 & 77.453 & 73.514 & 76.315 & 78.912 \\
\hline & POD & 2.374 & 2.112 & 2.351 & 2.456 & 2.198 \\
\hline & CAT & 0.5 & 0.466 & 0.521 & 0.498 & 0.507 \\
\hline & PAL & 34.972 & 35.861 & 36.331 & 34.579 & 35.431 \\
\hline \multirow[t]{4}{*}{ Tiber } & SOD & 145.038 & 135.245 & 148.942 & 146.721 & 139.578 \\
\hline & POD & 6.177 & 6.324 & 5.997 & 6.281 & 6.103 \\
\hline & CAT & 0.875 & 0.913 & 0.901 & 0.834 & 0.841 \\
\hline & PAL & 27.778 & 28.647 & 26.568 & 27.647 & 29.014 \\
\hline \multirow[t]{4}{*}{ Marco Polo } & SOD & 115.204 & 118.317 & 111.654 & 120.318 & 114.879 \\
\hline & POD & 1.693 & 1.587 & 1.654 & 1.721 & 1.803 \\
\hline & CAT & 0.959 & 0.972 & 1.051 & 0.967 & 0.936 \\
\hline & PAL & 30.806 & 32.341 & 28.976 & 31.514 & 30.847 \\
\hline \multirow[t]{4}{*}{ Francia } & SOD & 91.336 & 89.691 & 93.576 & 88.634 & 94.106 \\
\hline & POD & 1.854 & 1.924 & 1.796 & 1.846 & 1.899 \\
\hline & CAT & 0.084 & 0.112 & 0.097 & 0.132 & 0.091 \\
\hline & PAL & 45.056 & 44.312 & 46.873 & 45.344 & 47.325 \\
\hline \multirow[t]{4}{*}{ Rodina } & SOD & 138.612 & 136.577 & 140.613 & 143.687 & 138.316 \\
\hline & POD & 3.294 & 3.251 & 3.326 & 3.333 & 3.198 \\
\hline & CAT & 0.208 & 0.215 & 0.198 & 0.189 & 0.231 \\
\hline & PAL & 37.139 & 39.312 & 38.647 & 35.664 & 36.978 \\
\hline
\end{tabular}

$\overline{{ }^{z} \text { Comparisons were made in the horizontal direction using Duncan's }}$ multiple range test, and no significant difference was observed between the different detection time points in each cultivar.

proteases, and SOD in the leaves of resistant and susceptible cotton (Gossypium hirsutum) genotypes infected by Cotton leaf curl Burewala virus. Their results showed that PAL, POD, $\mathrm{CAT}$, and SOD have active roles in disease resistance against Cotton leaf curl Burewala virus. Decreased CAT activity was also detected in Urdbean leaf crinkle virus-infected leaves (Srivastava and Singh, 2010). Different defense-related enzymes

Table 2. Superoxide dismutase (SOD) activity of each of seven Lilium oriental cultivars after inoculation with Botrytis elliptica.

\begin{tabular}{lllrrrr}
\hline & & \multicolumn{5}{c}{ SOD activity (U/g) } \\
\cline { 3 - 7 } Reaction to B. elliptica & Cultivar & \multicolumn{1}{c}{ Control } & Day 3 & Day 5 & Day 7 & Day 9 \\
\hline High resistance & Constanta & $82.158 \mathrm{c}^{\mathrm{z}}$ & $228.235 \mathrm{a}$ & $119.474 \mathrm{~b}$ & $121.324 \mathrm{~b}$ & $116.911 \mathrm{~b}$ \\
& Siberia & $30.293 \mathrm{~d}$ & $171.765 \mathrm{c}$ & $250.542 \mathrm{a}$ & $224.788 \mathrm{~b}$ & $157.235 \mathrm{c}$ \\
& Sorbonne & $75.732 \mathrm{~d}$ & $179.608 \mathrm{~b}$ & $254.264 \mathrm{a}$ & $131.794 \mathrm{c}$ & $125.033 \mathrm{c}$ \\
Medium resistance & Tiber & $145.038 \mathrm{~b}$ & $207.844 \mathrm{a}$ & $218.876 \mathrm{a}$ & $94.226 \mathrm{c}$ & $111.869 \mathrm{c}$ \\
& Marco Polo & $115.204 \mathrm{c}$ & $122.353 \mathrm{c}$ & $161.529 \mathrm{~b}$ & $197.691 \mathrm{a}$ & $157.340 \mathrm{~b}$ \\
High susceptibility & Francia & $91.336 \mathrm{c}$ & $109.020 \mathrm{c}$ & $198.805 \mathrm{a}$ & $168.745 \mathrm{~b}$ & $174.309 \mathrm{~b}$ \\
& Rodina & $138.612 \mathrm{c}$ & $129.412 \mathrm{c}$ & $229.391 \mathrm{a}$ & $181.678 \mathrm{~b}$ & $135.285 \mathrm{c}$
\end{tabular}

${ }^{\mathrm{z}} \mathrm{A}$ different letter or letter combination indicates a significant difference at the 0.01 level between different days after inoculation in the same cultivar according to Duncan's multiple range test. function in different plants. Therefore, the activities of different defensive enzymes vary in different plants after infection and are highly complex.

The genus Lilium is native to the northern hemisphere, including Asia, Europe, and North America, and includes 100 species (McRae, 1998). Lilies have substantial ornamental, medicinal, and edible values, and they are one of the most important cut flowers worldwide (Mollaei et al., 2018). With the continuous expansion of lily cultivation, lily disease is becoming increasingly serious; furthermore, leaf blight (Botrytis elliptica) is a major threat to lily production worldwide (Chang et al., 2001) and has been recorded in many countries (Elad et al., 2007). Leaf blight is caused by B. elliptica, a necrotrophic pathogen that infects only lilies (Van Baarlen et al., 2007; Weiberg et al., 2013). An outbreak of leaf blight can reduce lily yield by $20 \%$ to $30 \%$, or even cause a total loss of production (Chang et al., 2001; Li, 1994; Tang et al., 1998; Wang et al., 1990). The use of resistant cultivars is the safest, most economical, and most effective option for managing leaf blight. Unfortunately, no immune lily cultivar has been reported. Therefore, the development of cultivars with stronger resistance to leaf blight is necessary to alleviate future threats to lily.

Different lily cultivars display clear differences in resistance to leaf blight. Zhu et al. (2010) identified the resistance of seven Lilium oriental hybrid cultivars, Constanta, Siberia, Sorbonne, Marco Polo, Tiber, Francia, and Rodina. Their results showed that the resistance levels of these seven cultivars were significantly different and could be divided into highly resistant (Constanta, Sorbonne, Siberia), moderately resistant (Marco Polo, Tiber), and highly susceptible (Francia, Rodina) groups. Based on the resistance distribution in the F1 population of 'Sorbonne' and 'Francia', Hu et al. (2017) identified the genetic transmission pattern of leaf blight resistance in Lilium species. Their results showed that the disease resistance of 'Sorbonne' could be inherited and was a typical quantitative trait determined by polygenes. Disease resistance in plants is associated with the activation of a wide array of defense responses that slow or halt infection at certain stages of host-pathogen interactions. Plants have evolved various preexisting physical and chemical barriers as well as inducible defense responses that interfere with pathogen establishment (Jones and Dangl 2006; Siddique et al., 2014; Vanitha et al., 2009; Zhao et al., 2008). However, the improvement of leaf blight resistance will require comprehensive studies and an understanding of the adaptive mechanisms and responses to $B$. elliptica infection that allow the survival of lily plants. At present, our knowledge of lily physiology, biochemistry, and molecular biology is limited. Moreover, to the best of our knowledge, there are no comprehensive studies of biochemical alterations in lily plants infected by B. elliptica. Therefore, the present study quantitatively estimated the activities of SOD, POD, CAT, and PAL and investigated their roles in response to B. elliptica inoculation in the seven Lilium oriental hybrids. The results can help establish physiological and biochemical characteristics for the selection of resistant lily sources and provide a theoretical basis for disease control and resistance breeding. 


\section{Materials and Methods}

EXPERIMENTAL MATERIALs. Bulbs of seven Lilium oriental hybrid cultivars (Constanta, Siberia, Sorbonne, Marco Polo, Tiber, Francia, and Rodina) were purchased from Beijing BiXi Floral Co. (Beijing, China) and planted in the greenhouse of the Landscaping Experimental Center of Nanjing Forestry University, Nanjing, China. The greenhouse was kept at an optimum temperature $\left(22{ }^{\circ} \mathrm{C}\right)$ and humidity $(>90 \%)$ for leaf blight incidence. The culture medium was composed of perlite, peat, and vermiculite in a ratio of $1: 1: 1$. All the materials were planted in early March.

InOCULATION. The inoculum was isolated and provided by the Plant Protection Department of Jinling Institute of Technology (Nanjing, China). B. elliptica spores grown on potato dextrose agar medium for $7 \mathrm{~d}$ were washed out with sterile water and adjusted to a concentration of $1 \times 10^{5}$ to $5 \times 10^{5} \mathrm{cfu} /$ $\mathrm{mL}$. The seven Lilium oriental hybrids were inoculated by spraying at the time when their buds first became visible.

Sample Collection. Samples were collected five times: on the first day before inoculation and on days 3, 5, 7, and 9 after inoculation. Upper, middle, and lower leaves were randomly picked from 10 plants for each hybrid. They were mixed, washed, and dried; then, the petioles were cut off. The blades were cut into $\approx 1.0-\times 1.5-\mathrm{cm}$ pieces, quickly weighed to obtain $0.3-$ and $1.0-\mathrm{g} / \mathrm{bag}$ samples, and placed in $\mathrm{a}-80{ }^{\circ} \mathrm{C}$ freezer.

Three replicates of each sample were stored. For each hybrid, uninoculated plants were used as the control.

Enzyme extraction. SOD, POD, and CAT were extracted according to Guan et al. (2012). For this purpose, $3 \mathrm{~mL}$ of precooled phosphate buffer solution [PBS $\left.\left(0.2 \mathrm{~mol} \cdot \mathrm{L}^{-1}, \mathrm{pH} 7.0\right)\right]$ and $0.06 \mathrm{~g}$ of polyvinyl pyrrolidone (PVP) were added to $0.6 \mathrm{~g}$ of frozen lily leaves. The material was then ground into homogenate in an ice bath and transferred to a $10-\mathrm{mL}$ centrifuge tube. The mortar was washed twice with $4 \mathrm{~mL}$ PBS, which was then also placed into the $10-\mathrm{mL}$ centrifuge tube. The volume was adjusted to $8 \mathrm{~mL}$, and the mixture was centrifuged at $3{ }^{\circ} \mathrm{C}$ and $8500 g_{\mathrm{n}}$ for $30 \mathrm{~min}$. The supernatant was the enzyme crude extract, and it was stored at $-80^{\circ} \mathrm{C}$. PAL was extracted according to Sun et al. (2004) as follows: leaf samples weighing $0.6 \mathrm{~g}$ were placed in $6 \mathrm{~mL}$ of prechilled $0.1 \mathrm{~mol} \cdot \mathrm{L}^{-1}$ boric acid-borax buffer [pH 8.7; containing $1 \mathrm{mmol} \cdot \mathrm{L}^{-1}$ ethylenediaminetetraacetic acid (EDTA), $20 \mathrm{mmol} \cdot \mathrm{L}^{-1}$ mercaptoethanol], ground in an ice bath, filtered with 4 layers of gauze, and centrifuged at $20,000 g_{n}$ for 30 min at $4{ }^{\circ} \mathrm{C}$. The supernatant was removed and stored at $-80^{\circ} \mathrm{C}$.

MeASUREMENT OF LILY LEAF DEFENSE ENZYME ACTIVITY. SOD activity was determined by the nitrogen blue tetrazolium (NBT) method according to Song (2016) as follows: $1.5 \mathrm{~mL}$ of $0.05 \mathrm{~mol} \cdot \mathrm{L}^{-1} \mathrm{PBS}$ [ 1.55 for the control group $\left.(\mathrm{CK})\right], 0.3 \mathrm{~mL}$ of $130 \mathrm{mmol} \cdot \mathrm{L}^{-1}$ methionone (Met), $0.3 \mathrm{~mL}$ of $750 \mu \mathrm{mol} \cdot \mathrm{L}^{-1}$ nitro-blue tetrazolium (NBT), $0.3 \mathrm{~mL}$ of $100 \mu \mathrm{mol} \cdot \mathrm{L}^{-1}$ EDTA$\mathrm{Na}_{2}, 0.3 \mathrm{~mL}$ of $20 \mu \mathrm{mol} \cdot \mathrm{L}^{-1}$ riboflavin, $0.05 \mathrm{~mL}$ of enzyme solution ( 0 for $\mathrm{CK}$ ), and $0.25 \mathrm{~mL}$ of double-distilled $\mathrm{H}_{2} \mathrm{O}$ $\left(\mathrm{ddH}_{2} \mathrm{O}\right)$ for a total of $3.0 \mathrm{~mL}$ were mixed by shaking and reacted under $4000 \mathrm{l} \times$ light (natural light and fluorescent lamp) for $20 \mathrm{~min}$. The absorbance was measured at $560 \mathrm{~nm}$.

One SOD activity unit inhibits $50 \%$ of the NBT photochemical reduction and is calculated based on the following formula:

$$
\begin{aligned}
\text { SOD activity units per gram }= & \left(\mathrm{A}_{\mathrm{CK}}-\mathrm{A}_{\mathrm{E}}\right) \times \mathrm{V} /\left(\mathrm{A}_{\mathrm{CK}}\right. \\
& \left.\times 0.5 \times \mathrm{W} \times \mathrm{V}_{\mathrm{t}}\right),
\end{aligned}
$$

where $A_{C K}$ represents the optical density (OD) value of the $C K$, $\mathrm{V}$ is the total volume (milliliters), $\mathrm{A}_{\mathrm{E}}$ is the OD of the sample,
$\mathrm{V}_{\mathrm{t}}$ is the sample volume used, and $\mathrm{W}$ represents the fresh weight of the sample.

POD activity was measured by guaiacol colorimetry according to Song (2016) as follows: $10 \mathrm{~mL}$ of $2 \% \mathrm{H}_{2} \mathrm{O}_{2}, 29 \mathrm{~mL}$ of $0.05 \mathrm{~mol} \cdot \mathrm{L}^{-1} \mathrm{PBS}, 0.1 \mathrm{~mL}$ of enzyme solution (boiled $5 \mathrm{~min}$ for the $\mathrm{CK}$ ), and $10 \mathrm{~mL}$ of $0.05 \mathrm{~mol} \cdot \mathrm{L}^{-1}$ guaiacol solution were mixed, placed in a bath at $34{ }^{\circ} \mathrm{C}$ for $3 \mathrm{~min}$, and diluted twice. The absorbance was measured at $470 \mathrm{~nm}$ every $1 \mathrm{~min}$. The activity unit was the change in $A_{470}$ within $1 \mathrm{~min}$, and the activity was calculated using the following formula:

POD activity units per gram $=\Delta \mathrm{A}_{470}$

$$
\times \mathrm{V}_{\mathrm{t}} /\left(\mathrm{W} \times \mathrm{V}_{\mathrm{S}} \times 0.01 \times \mathrm{t}\right),
$$

where $\Delta \mathrm{A}_{470}$ is the change in OD during the reaction time, $\mathrm{V}_{\mathrm{t}}$ is the total volume of the enzyme, $\mathrm{W}$ is the fresh weight of the fresh leaves, $\mathrm{V}_{\mathrm{S}}$ is the sample volume used (milliliters), and $t$ is the reaction time (minutes).

The activity of CAT was measured using the following ultraviolet absorbance method of Chen et al. (2009): after the addition of $1.0 \mathrm{~mL}$ of distilled water, $1.5 \mathrm{~mL}$ of $\mathrm{pH} 7.8$ phosphate buffer, and $0.2 \mathrm{~mL}$ of enzyme solution, the mixture was warmed at $25{ }^{\circ} \mathrm{C}$ in a $10-\mathrm{mL}$ test tube and $0.3 \mathrm{~mL}$ of 0.1 $\mathrm{mol} \cdot \mathrm{L}^{-1} \mathrm{H}_{2} \mathrm{O}_{2}$ was added. The mixture was then poured into a quartz cuvette, and the change in absorbance at $240 \mathrm{~nm}$ was measured. The amount of enzyme that decreased $\mathrm{A}_{240}$ by 0.01 within 1 min was 1 enzyme unit (U), and the activity was calculated as follows:

$$
\text { CAT activity units per gram } \begin{aligned}
& =\Delta \mathrm{A}_{240} \\
& \times \mathrm{V}_{\mathrm{t}} /\left(\mathrm{W} \times \mathrm{V}_{\mathrm{S}} \times 0.1 \times \mathrm{t}\right),
\end{aligned}
$$
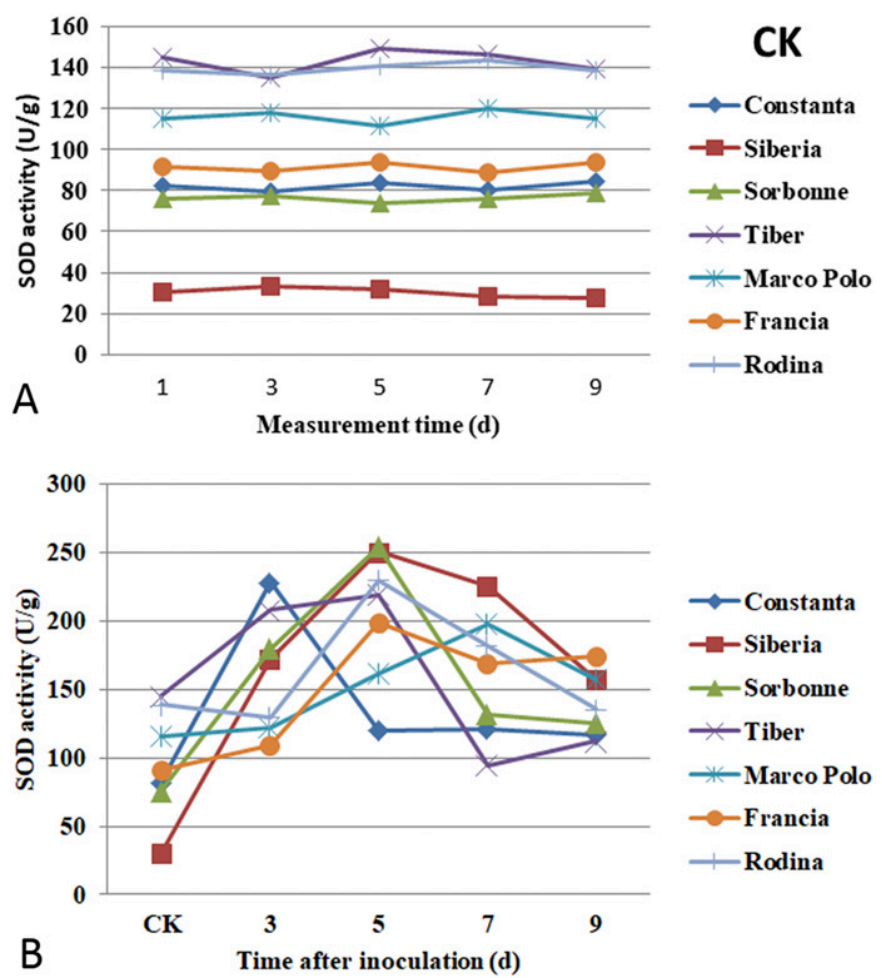

Fig. 1. Trends of changes in superoxide dismutase (SOD) activity in seven Lilium oriental cultivars after inoculation with Botrytis elliptica. (A) Changes in the uninoculated control group (CK) from day 1 to day 7. (B) Comparisons between the inoculated and CK plants of each cultivar. 
Table 3. Peroxidase (POD) activity of each of seven Lilium oriental cultivars after inoculation with Botrytis elliptica.

\begin{tabular}{lllcrrr}
\hline & & \multicolumn{5}{c}{ POD activity (U/g) } \\
\cline { 3 - 7 } Reaction to B. elliptica & Cultivar & Control & Day 3 & Day 5 & Day 7 & Day 9 \\
\hline High resistance & Constanta & $8.971 \mathrm{c}^{\mathrm{z}}$ & $10.336 \mathrm{bc}$ & $12.242 \mathrm{~b}$ & $11.682 \mathrm{~b}$ & $21.833 \mathrm{a}$ \\
& Siberia & $4.635 \mathrm{c}$ & $9.561 \mathrm{~b}$ & $12.384 \mathrm{a}$ & $9.835 \mathrm{~b}$ & $13.542 \mathrm{a}$ \\
& Sorbonne & $2.374 \mathrm{~d}$ & $7.966 \mathrm{ab}$ & $4.459 \mathrm{c}$ & $7.380 \mathrm{~b}$ & $9.556 \mathrm{a}$ \\
Medium resistance & Tiber & $6.177 \mathrm{c}$ & $7.871 \mathrm{bc}$ & $12.340 \mathrm{~b}$ & $18.279 \mathrm{a}$ & $15.549 \mathrm{ab}$ \\
& Marco Polo & $1.693 \mathrm{c}$ & $3.449 \mathrm{c}$ & $5.534 \mathrm{bc}$ & $7.626 \mathrm{~b}$ & $19.662 \mathrm{a}$ \\
High susceptibility & Francia & $1.854 \mathrm{c}$ & $2.885 \mathrm{c}$ & $5.369 \mathrm{bc}$ & $9.007 \mathrm{~b}$ & $22.872 \mathrm{a}$ \\
& Rodina & $3.294 \mathrm{c}$ & $4.881 \mathrm{bc}$ & $4.853 \mathrm{bc}$ & $5.167 \mathrm{~b}$ & $10.682 \mathrm{a}$ \\
\hline
\end{tabular}

${ }^{\mathrm{z}} \mathrm{A}$ different letter or letter combination indicates a significant difference at the 0.01 level between different days after inoculation in the same cultivar according to Duncan's multiple range test. highly resistant 'Siberia' and 1.69 times that in 'Constanta'. After inoculation with $B$. elliptica, SOD activities in the resistant cultivars increased more sharply than those in the other cultivars, with the fastest increase observed in 'Constanta' (Supplemental Table 1). Compared with that in the highly resistant cultivars, SOD activity in the moderately resistant cultivars did not change drastically. Furthermore, SOD activity in the moderately resistant cultivar Tiber also increased after inoculation, and it reached its where $\Delta \mathrm{A}_{240}$ is the change in OD during the reaction time, $t$ is the reaction time ( $\mathrm{min}), \mathrm{V}_{\mathrm{t}}$ is the total volume of the enzyme, $\mathrm{W}$ is the fresh weight of the fresh leaves, and $V_{S}$ is the sample volume used (milliliters).

PAL activity was measured according to the method published by Sun et al. (2004). We added $2.5 \mathrm{~mL}$ of extraction buffer to $0.5 \mathrm{~mL}$ of the aforementioned enzyme solution and 1 $\mathrm{mL}$ of $0.02 \mathrm{~mol} \cdot \mathrm{L}^{-1} \mathrm{~L}$-phenylalanine (prepared with $0.1 \mathrm{~mol} \cdot \mathrm{L}^{-1}$ boric acid-borax buffer, $\mathrm{pH} 8.7$ ), and the mixture was allowed to react at $40{ }^{\circ} \mathrm{C}$ for $1 \mathrm{~h}$. The reaction was then stopped by placing it in an ice bath, and the OD was measured at $290 \mathrm{~nm}$. PAL activity was calculated using the following formula:

PAL activity units per gram $=\Delta \mathrm{A}_{290} \times \mathrm{V}_{\mathrm{t}} /(\mathrm{W}$

$$
\left.\times \mathrm{V}_{\mathrm{S}} \times 0.01 \times \mathrm{t}\right)
$$

where $\Delta \mathrm{A}_{290}$ is the change in OD during reaction time, $t$ is the reaction time (minutes), $\mathrm{V}_{\mathrm{t}}$ is the total volume of the enzyme, $\mathrm{W}$ is the fresh weight of the fresh leaves, and $V_{S}$ is the sample volume used (milliliters).

Statistical analysis. The experiments were performed using a completely randomized design with three replicates. All data were subjected to one-way analysis of variance (ANOVA), and mean comparisons were performed using Duncan's multiple range test, with significant difference defined as $P \leq 0.01$ using SPSS software (version 19.0 for Windows; IBM Corp., Armonk, NY).

\section{Results}

Changes in SOD activity. As shown in Table 1, SOD activity in the control of each cultivar showed no significant change from day 1 to day 7 . However, SOD activity in the plants inoculated with $B$. elliptica changed dramatically. Changes in SOD activity in the leaves of the seven Lilium oriental cultivars with different levels of resistance after inoculation with $B$. elliptica are shown in Table 2 and Fig. 1. Before inoculation, the SOD concentration of all cultivars was relatively low. SOD activities in the three highly resistant cultivars, Siberia, Sorbonne, and Constanta, were lower than those in the four moderately resistant and highly susceptible cultivars (Hu et al., 2017). The two cultivars with the highest activities were the moderately resistant cultivar Tiber and the highly susceptible cultivar Rodina. The initial SOD activity in 'Tiber' was 4.79 times that in the highly resistant cultivar Siberia, which was 1.77 times that in 'Constanta'. SOD activity in the highly susceptible cultivar Rodina was 4.58 times that in first peak on the third day of inoculation; then, the upward trend weakened. However, SOD activity reached a second peak on day 5; then, it declined rapidly. In another moderately resistant cultivar, Marco Polo, SOD activity increased slowly after inoculation and peaked on day 7. Additionally, SOD activity of the susceptible cultivar Francia also showed slight increases of $\approx 7.684$ and $107.469 \mathrm{U} / \mathrm{g}$ on day 3 and day 5 after inoculation; then, it began to decline after reaching 198.805 $\mathrm{U} / \mathrm{g}$ on day 5 . In 'Rodina', another susceptible cultivar, SOD activity first decreased and then increased. On day 5 , it peaked at $229.391 \mathrm{U} / \mathrm{g}$. By comparing the SOD activities of the resistant and susceptible cultivars, it was apparent that a change in SOD activity within a short time after inoculation was strongly associated with lily resistance. After inoculation, the SOD activity in the highly resistant cultivars always increased
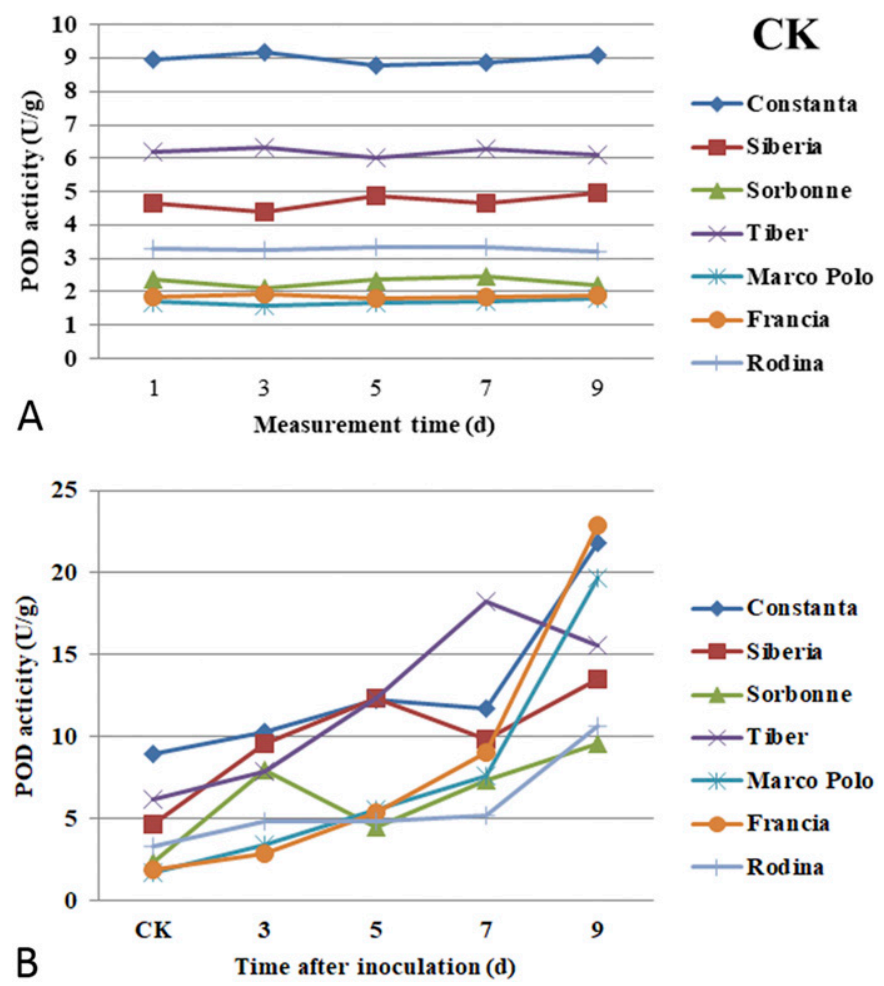

Fig. 2. Trends of changes in peroxidase (POD) activity in seven Lilium oriental cultivars after inoculation with Botrytis elliptica. (A) Changes in the uninoculated control group (CK) from day 1 to day 7. (B) Comparisons between the inoculated and CK plants of each cultivar. 
Table 4. Catalase (CAT) activity of each of seven Lilium oriental cultivars after inoculation with Botrytis elliptica.

\begin{tabular}{lllllll}
\hline & & \multicolumn{5}{c}{ CAT activity $(\mathrm{U} / \mathrm{g})$} \\
\cline { 3 - 7 } Reaction to B. elliptica & Cultivar & Control & Day 3 & Day 5 & Day 7 & Day 9 \\
\hline High resistance & Constanta & $1.375 \mathrm{a}^{\mathrm{z}}$ & $1.833 \mathrm{a}$ & $1.251 \mathrm{ab}$ & $0.833 \mathrm{~b}$ & $0.251 \mathrm{~b}$ \\
& Siberia & $1.063 \mathrm{a}$ & $1.167 \mathrm{a}$ & $0.833 \mathrm{a}$ & $0.333 \mathrm{~b}$ & $0.251 \mathrm{~b}$ \\
& Sorbonne & $0.5 \mathrm{~b}$ & $1.584 \mathrm{a}$ & $1.251 \mathrm{a}$ & $0.584 \mathrm{~b}$ & $0.333 \mathrm{~b}$ \\
Medium resistance & Tiber & $0.875 \mathrm{a}$ & $0.5 \mathrm{ab}$ & $0.667 \mathrm{ab}$ & $0.458 \mathrm{~b}$ & $0.333 \mathrm{~b}$ \\
& Marco Polo & $0.959 \mathrm{ab}$ & $1.167 \mathrm{ab}$ & $1.416 \mathrm{a}$ & $0.667 \mathrm{~b}$ & $0.292 \mathrm{~b}$ \\
High susceptibility & Francia & $0.084 \mathrm{~b}$ & $0.208 \mathrm{c}$ & $0.333 \mathrm{a}$ & $0.084 \mathrm{~b}$ & $0.084 \mathrm{c}$ \\
& Rodina & $0.208 \mathrm{c}$ & $0.5 \mathrm{~b}$ & $0.625 \mathrm{a}$ & $0.251 \mathrm{c}$ & $0.167 \mathrm{c}$ \\
\hline
\end{tabular}

${ }^{\mathrm{z}} \mathrm{A}$ different letter or letter combination indicates a significant difference at the 0.01 level between different days after inoculation in the same cultivar according to Duncan's multiple range test. inoculation, and that in two cultivars, Sorbonne and Marco Polo, began to decrease from the third day. POD enzyme activity increased dramatically from day 7 in all cultivars except Tiber. No significant relationship was determined between leaf blight resistance and POD activity.

Changes in CAT activity. In each of the seven Lilium oriental cultivars, the CAT activities in the CK plants showed no significant changes from day 1 to day 7 (Table 1). The changes in CAT activity in the seven Lilium oriental cultivars after inoculation with B. elliptica are shown in Table 4 and Fig. 3. Before inoculation, the CAT activities in the two resistant cultivars, Constanta and Siberia, were significantly higher than those in the two susceptible cultivars, Francia and Rodina. However, the other resistant cultivar, Sorbonne, showed low CAT activity. After inoculation, the CAT activity in 'Sorbonne' increased sharply to $1.584 \mathrm{U} / \mathrm{g}$, which was only $0.249 \mathrm{U} / \mathrm{g}$ lower than that in 'Constanta'. All three resistant cultivars reached peaks of CAT activity at day 3 after inoculation (Table 4; Supplemental Table 3). The CAT activity in the moderately resistant cultivar Marco Polo also increased significantly after inoculation. However, the CAT activity in another moderately resistant cultivar, Tiber, showed a different reaction, with a sharp decrease after inoculation. Although the CAT activity increased to a certain degree, it never exceeded the activity before inoculation. The CAT activity of the two susceptible cultivars Francia and Rodina showed a similar trend after inoculation: a slow increase followed by a decrease after day 5 . The CAT activity in all seven cultivars decreased after day 5 , and all reached similar levels that ranged from 0.084 (Francia) to $0.333 \mathrm{U} / \mathrm{g}$ (Sorbonne and Tiber).

Changes in PAL activity. In each of the seven Lilium oriental cultivars, the PAL activities of the control plants showed no significant changes from day 1 to day 7 (Table 1). The changes in PAL activities in the seven Lilium oriental cultivars with different resistance levels after inoculation with B. elliptica are shown in Table 5 and Fig. 4. Before inoculation, PAL activities in all the cultivars except Francia were similar. PAL activities in the highly susceptible cultivars were higher than those in the highly resistant and moderately resistant cultivars. After inoculation, PAL activity in the highly resistant cultivar Constanta increased, reaching its first peak on day 3 and its second peak on day 7 (Supplemental Table 4). PAL activity in 'Sorbonne' increased slightly; then, it decreased sharply to its minimum on day 7. However, that in 'Siberia' decreased sharply and reached its minimum on day 3 ; then, it increased to $35.889 \mathrm{U} / \mathrm{g}$ on day 9 . One moderately resistant cultivar, Tiber, showed behavior similar to that of the cultivar Sorbonne, but it reached its minimum on day 5 . The most dramatic change occurred in the moderately resistant cultivar Marco Polo. The two highly susceptible cultivars Francia and Rodina also showed completely different patterns of PAL activity: that in the cultivar Francia increased and then decreased, whereas that in the cultivar Rodina decreased sharply and then increased. Therefore, changes in PAL activity showed differences among different cultivars, but not among the resistance characteristics. 
Table 5. Phenylalanine ammonia-lyase (PAL) activity of each of seven Lilium oriental cultivars after

\begin{tabular}{lllclcc}
\hline & & \multicolumn{5}{c}{ PAL activity (U/g) } \\
\cline { 3 - 7 } Reaction to B. elliptica & Cultivar & Control & Day 3 & Day 5 & Day 7 & Day 9 \\
\hline High resistance & Constanta & $36.972 \mathrm{~b}^{\mathrm{z}}$ & $49.667 \mathrm{a}$ & $49.194 \mathrm{a}$ & $51.472 \mathrm{a}$ & $41.944 \mathrm{~b}$ \\
& Siberia & $34.472 \mathrm{a}$ & $27.722 \mathrm{~b}$ & $31.333 \mathrm{ab}$ & $35.028 \mathrm{a}$ & $35.889 \mathrm{a}$ \\
& Sorbonne & $34.972 \mathrm{a}$ & $35.861 \mathrm{a}$ & $30.583 \mathrm{~b}$ & $24.611 \mathrm{c}$ & $35.861 \mathrm{a}$ \\
Medium resistance & Tiber & $27.778 \mathrm{~b}$ & $29.222 \mathrm{~b}$ & $20.028 \mathrm{c}$ & $36.472 \mathrm{a}$ & $36.111 \mathrm{a}$ \\
& Marco Polo & $30.806 \mathrm{~cd}$ & $31.5 \mathrm{c}$ & $42.306 \mathrm{a}$ & $27.5 \mathrm{~d}$ & $37.444 \mathrm{~b}$ \\
High susceptibility & Francia & $45.056 \mathrm{ab}$ & $49.639 \mathrm{a}$ & $45.806 \mathrm{ab}$ & $42.167 \mathrm{~b}$ & $39.056 \mathrm{~b}$ \\
& Rodina & $37.139 \mathrm{a}$ & $23.361 \mathrm{~b}$ & $28.75 \mathrm{~b}$ & $42.944 \mathrm{a}$ & $43.222 \mathrm{a}$ \\
& & &
\end{tabular}

${ }^{\mathrm{z}} \mathrm{A}$ different letter or letter combination indicates a significant difference at the 0.01 level between different days after inoculation in the same cultivar according to Duncan's multiple range test. inoculation with Botrytis elliptica.

materials and time points before inoculation as controls, this study analyzed the changes in the activities of PAL, SOD, POD, and CAT in the leaves of Lilium oriental hybrids with different levels of resistance in response to B. elliptica.

According to the results of this study, the activity levels of both SOD and CAT were significantly correlated with resistance, and these results were consistent with those of reports of other plant resistance functions (Chen et al., 2008; Zhang et al., 2016). SOD participates in the
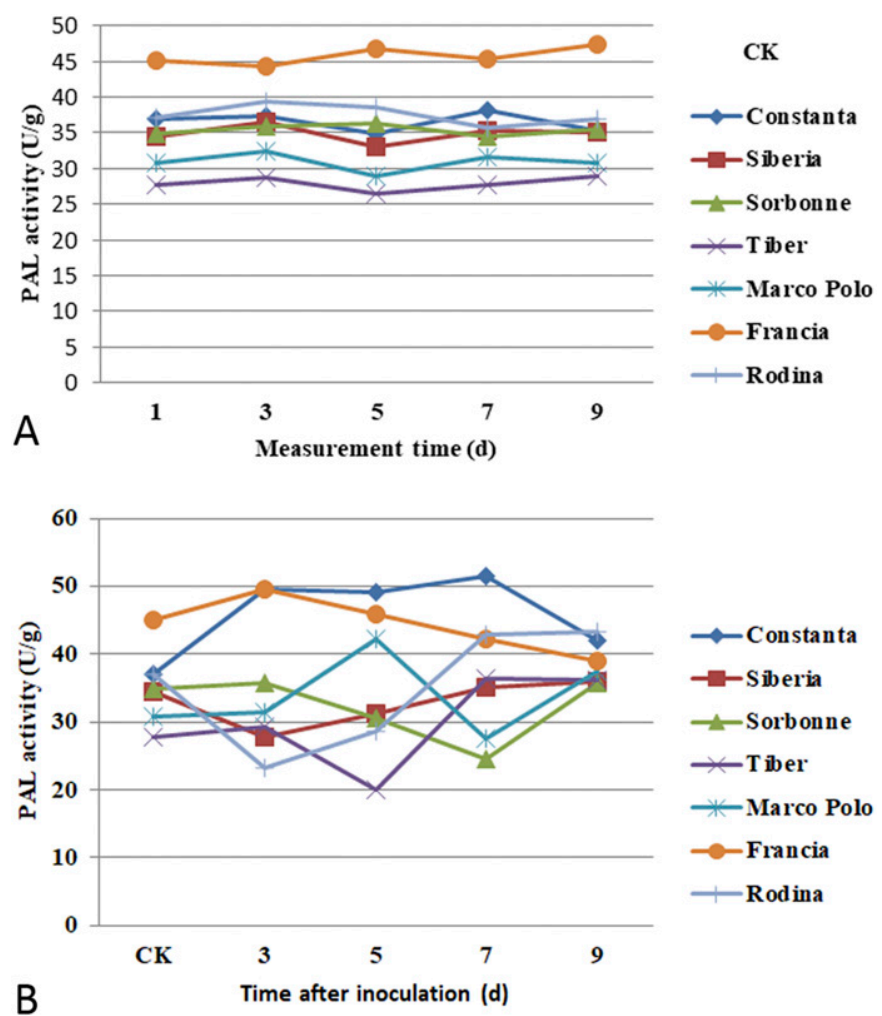

Fig. 4. Trends of changes in phenylalanine ammonia-lyase (PAL) activity in seven Lilium oriental cultivars after inoculation with Botrytis elliptica. (A) Changes in the uninoculated control group (CK) from day 1 to day 7. (B) Comparisons between the inoculated and CK plants of each cultivar.

\section{Discussion}

Early and elevated levels of the expression of various defense enzymes are an important feature of plant resistance to pathogens (Vanitha and Umesha 2008). Plants defend themselves against pathogen challenges by activating defense response pathways and developing complex antioxidant defense systems that respond to pathogens (Kawaoka et al., 2003; Lee and Hwang, 2005). However, although a clear-cut correlation between defense-related enzyme activities and plant resistance has been established, the rules, characteristics, and mechanisms of defense reactions and their relationships with different plant diseases remain unclear (de Armas et al., 2007; Modafar et al., 2006; Santiago et al., 2010). Using uninoculated scavenging of active oxygen. It is at the core of the antioxidant enzyme system and is widely distributed in both plants and animals. As reported for Glycine max (soybean), Brassica rapa pekinensis (chinese cabbage), and Arabidopsis thaliana (Ma and Zhu, 2003), when subjected to external stress, plants with strong resistance have significantly higher SOD activity than plants with weak resistance. The expression of SOD is also related to plant stress resistance (Zhang et al., 2016). The results of our study were consistent with the results of those previous reports. After inoculation with $B$. elliptica, SOD activity increased rapidly in the highly resistant Lilium oriental hybrid cultivars Constanta, Siberia, and Sorbonne (Supplemental Table 1). Although SOD activity also increased in two highly susceptible cultivars, Francia and Rodina, the response time and range of increase were far lower than those in the highly resistant cultivars. Therefore, the change in SOD activity appeared to be an important physiological basis for resistance to B. elliptica.

CAT mainly affects plant disease resistance through two physiological pathways. First, the plant resistance factor salicylic acid (SA) can inhibit the activity of CAT and generate excessive reactive oxygen species (ROS), resulting in systemicacquired resistance (SAR) (Dat et al., 2003). During the onset of oxidative stress due to infestation by pathogenic microorganisms, CAT decomposes $\mathrm{H}_{2} \mathrm{O}_{2}$, generates oxygen molecules, and triggers the generation of SA via benzoic acid, thus leading to SAR reactions (Jones, 1996). Second, another resistance signal factor in plants, methyl jasmonate (MeJA), participates in a defense response that is not dependent on SA; instead, it has a synergistic effect on SA. For example, SA can enhance $\beta$-galactosidase (GUS) expression driven by the oxidative stress marker AoPR10, which is also regulated by MeJA, but CAT exerts an inhibitory effect. However, $\mathrm{H}_{2} \mathrm{O}_{2}$ is an intermediate effector of the two defense pathways mentioned (Mur et al., 2006). In this study, there was a difference in CAT activity between the highly resistant and highly susceptible hybrids; this suggested that altered CAT activity also had an important effect on leaf blight resistance. This result is consistent with previous results found for Brassica juncea (Pandey et al., 2017) and Gossypium (Siddique et al., 2014). However, the physiological pathway by which CAT affects resistance to $B$. elliptica remains unclear and requires further investigations and experiments.

The activities of PAL and POD have been reported to be related to plant stress resistance (Pandey et al., 2017; Yu et al., 2012). Farahani and Taghavi (2018) found that rutin-induced resistance against Xanthomonas perforans in tomato (Solanum 
lycopersicum) might be mediated through the stimulation of some defense genes, which included PAL. They also found that PAL activity was higher in the leaves of uninoculated plants of a susceptible genotype than in those of a resistant genotype; however, it decreased to the lowest value after inoculation (Siddique et al., 2014). In this study, significant changes in POD and PAL activity occurred after inoculation with $B$. elliptica in all seven Lilium oriental hybrids. There were also some differences among the cultivars, but these differences did not clearly correspond to the highly resistant and highly susceptible categories the way SOD and CAT did. There have been reports of resistance to B. elliptica among Lilium oriental hybrids, but no immune hybrid has been reported. Differences were observed in the times when plants began to show lesions after inoculation. As we reported previously (Hu et al., 2017), hybrids that showed obvious lesions from the second day after inoculation were determined to be highly susceptible, whereas those that did not show significant lesions even on day 8 after inoculation were considered highly resistant. However, all hybrids began to show lesions from day 8 after inoculation. No immune hybrid was found.

Disease resistance in plants is a complex process involving many physiological and biochemical reactions (Choudhary and Varma, 2016; Huang, 2001). The results of the changes in defensive enzyme activity are far from sufficient to explain Lilium leaf blight resistance. To understand Lilium resistance physiology more clearly, other physiological indicators such as endogenous hormones and osmoregulation should be considered.

The results of this study indicated that SOD and CAT have active roles in disease resistance against leaf blight; however, there was no direct connection between leaf blight resistance and PAL and POD activities. These findings can help us understand the resistance physiology of leaf blight and provide indicators for Lilium breeding. However, the mechanisms by which SOD and CAT accumulation contribute to resistance in lily remain to be explored in future studies.

\section{Literature Cited}

Chang, S.W., S.K. Kim, and B.K. Hwang. 2001. Gray mold of day lily (Hemerocallis fulva L.) caused by Botrytis elliptica in Korea. Plant Pathol. J. 17:305-307.

Chen, G., C.X. Yan, C.J. Li, Y.T. Zhang, and S.H. Shang. 2009. Changes of peanut peroxidase and catalase activity before and after aflatoxin infection. Shandong Agr. Sci. 2009:12-14 (in Chinese with English abstract).

Chen, J.F., G.N. Wang, and S.M. Cheng. 2008. Progress about catalase function in plant stress reactions. Xibei Zhiwu Xuebao 2008:188 193 (in Chinese with English abstract).

Choodamani, M.S., P. Hariprasad, M.K. Sateesh, and S. Umesha. 2009. Involvement of catalase in bacterial blight disease development of rice caused by Xanthomonas oryzae pv. Oryza. Intl. J. Pest Mgt. 55:121-127.

Choudhary, D.K. and A. Varma. 2016. Microbial-mediated induced systemic resistance in plants. Springer, Singapore.

Dat, J.F., R. Pellinen, T. Beeckman, B. Van De Cotte, C. Langebartels, J. Kangasjärvi, D. Inzé, and F. Van Breusegem. 2003. Changes in hydrogen peroxide homeostasis trigger an active cell death process in tobacco. Plant J. 33:621-632.

de Armas, R., R. Santiago, M.E. Legaz, and C. Vicente. 2007. Levels of phenolic compounds and enzyme activity can be used to screen for resistance of sugarcane to smut (Ustilago scitaminea). Australas. Plant Pathol. 36:32-38.

Ehsani-Moghaddam, B., M.T. Charles, O. Carisse, and S. Khanizadeh. 2006. Superoxide dismutase responses of strawberry cultivars to infection by Mycosphaerella fragariae. J. Plant Physiol. 163:147153.

Elad, Y., B. Williamson, P. Tudzynski, N. Delen, Y. Elad, and B. Williamson. 2007. Botrytis: Biology, pathology and control. Springer, Dordrecht, The Netherlands.

Espinosa-Leal, C.A., C.A. Puente-Garza, and S. García-Lara. 2018. In vitro plant tissue culture: Means for production of biological active compounds. Planta 2018:1-18.

Farahani, A.S. and S.M. Taghavi. 2018. Rutin promoted resistance of tomato against Xanthomonas perforans. Eur. J. Plant Pathol. 151:527-531.

Guan, L., F. Luo, R. Guo, and F. Hu. 2012. Effect of pH on the activity of the crude extract enzyme from lily leaves. Jiangsu Agr. Sci. 40:147-149 (in Chinese).

Hameed, A. and N. Iqbal. 2014. Chemo-priming with mannose, mannitol and $\mathrm{H}_{2} \mathrm{O}_{2}$ mitigate drought stress in wheat. Cereal Res. Commun. 42:450-462.

Hemm, M.R., S.D. Rider, J. Ogas, D.J. Murry, and C. Chapple. 2004. Light induces phenylpropanoid metabolism in Arabidopsis roots. Plant J. 38:765-778.

Hu, F., G. Liu, Y. Hu, R. Guo, L. Zhu, F. Luo, and F. Wang. 2017. Authenticity identification and leaf blight resistance evaluation of the F1 hybrids from two Lilium, cultivars 'Sorbonne' and 'Francia'. Physiol. Mol. Plant Pathol. 100:194-200.

Huang, J. 2001. Plant pathogenesis and resistance. Springer, Dordrecht, The Netherlands.

Ighodaro, O.M. and O.A. Akinloye. 2017. First line defence antioxidants-superoxide dismutase (SOD), catalase (CAT) and glutathione peroxidase (GPX): Their fundamental role in the entire antioxidant defence grid. Alexandria J. Med.doi: 10.1016/j.ajme.2017.09.001.

Jayaraj, J., R. Bhuvaneswari, R. Rabindran, S. Muthukrishnan, and R. Velazhahan. 2010. Oxalic acid-induced resistance to Rhizoctonia solani in rice is associated with induction of phenolics, peroxidase and pathogenesis-related proteins. J. Plant Interact. 5:147-157.

Jones, J. 1996. Plant pathology. Paranoid plants have their genes examined. Curr. Biol. 4:749-751.

Jones, J.D.G. and J.L. Dangl. 2006. The plant immune system. Nature 444:323-329.

Kawaoka, A., E. Matsunaga, S. Endo, S. Kondo, K. Yoshida, A. Shinmyo, and H. Ebinuma. 2003. Ectopic expression of a horseradish peroxidase enhances growth rate and increases oxidative stress resistance in hybrid aspen. Plant Physiol. 132:1177-1185.

Lee, S.C. and B.K. Hwang. 2005. Induction of some defense-related genes and oxidative burst is required for the establishment of systemic acquired resistance in Capsicum annuum. Planta 221:790-800.

Li, C. 1994. Causes and countermeasures of summer death of edible lily in Gansu. Plant Protection Technol. Ext. 1994:13-14 (in Chinese with English abstract).

Ma, X. and D. Zhu. 2003. Functional roles of the plant superoxide dismutase. Hereditas 25:225-231 (in Chinese).

McRae, E.A. 1998. Lilies: A guide for growers and collectors. Timber Press, Portland, OR.

Modafar, C., E. Boustani, B. Rahioui, A. Meziane, and Z. AlaouiTalibi. 2006. Suppression of phenylalanine ammonia-lyase activity elicited in date palm by Fusarium oxysporum f. sp. albedinis hyphal wall elicitor. Biol. Plant. 50:697-700.

Mollaei, S., H. Farahmand, and I. Tavassolian. 2018. The effects of 24-epibrassinolide corm priming and foliar spray on morphological, biochemical, and postharvest traits of sword lily. Hort. Environ. Biotechnol. 59:1-9.

Mur, L.A.J., P. Kenton, R. Atzorn, O. Miersch, and C. Wasternack. 2006. The outcomes of concentration-specific interactions between salicylate and jasmonate signaling include synergy, antagonism, and oxidative stress leading to cell death. Plant Physiol. 140:249-262.

Pandey, V., A.K. Tewari, and D. Saxena. 2017. Activities of defensive antioxidant enzymes and biochemical compounds induced by 
bioagents in Indian mustard against alternaria blight. Proc. Natl. Acad. Sci. India 2:1-10.

Patel, S.J., R.B. Subramanian, and Y.S. Jha. 2011. Biochemical and molecular studies of early blight disease in tomato. Phytoparasitica 39:269-283.

Santiago, R., R.D. Armas, M. Blanch, C. Vicente, and M.E. Legaz. 2010. In vitro effects of caffeic acid upon growth of the fungi Sporisorium scitamineum. J. Plant Interact. 5:233-240.

Siddique, Z., K.P. Akhtar, A. Hameed, N. Sarwar, I.U. Haq, and S.A. Khan. 2014. Biochemical alterations in leaves of resistant and susceptible cotton genotypes infected systemically by cotton leaf curl Burewala virus. J. Plant Interact. 9:702-711.

Song, X.Y. 2016. Physiological responses of Asian lilies under Botrytis cinerea stress and cloning of the regulatory gene $M A P K$. Diss., Shenyang Agr. Univ., Shenyang, China (in Chinese with English abstract).

Srivastava, S. and A. Singh. 2010. Changes in catalase activity and total protein content in urdbean [Vigna mungo (L.) Hepper] plants as a result of ULCV infection. Indian J. Soc. Res. 1:67-69.

Sun, H., T. Li, and Y. Li. 2004. Changes of phenols content and activity of enzymes related to phenols in lily bulbs stored at different cold temperatures for breaking dormancy. Zhongguo Nong Ye Ke Xue 37:1777-1782 (in Chinese with English abstract).

Tahsili, J., M. Sharifi, N. Safaie, S. Esmaeilzadeh-Bahabadi, and M. Behmanesh. 2014. Induction of lignans and phenolic compounds in cell culture of Linum album by culture filtrate of Fusarium graminearum. J. Plant Interact. 9:412-417.

Tang, X., A. Xiao, C. You, Y. Zeng, G. Peng, W. Liu, and D. Zhang. 1998. A study on the biological properties of Botrytis elliptica causing lily gray mould. Acta Agriculturae Universitis Jiangxiensis 20:485-489 (in Chinese with English abstract).
Van Baarlen, P., E.J. Woltering, M. Staats, and J.A. van Kan. 2007. Histochemical and genetic analysis of host and non-host interactions of Arabidopsis with three Botrytis species: An important role for cell death control. Mol. Plant Pathol. 8:41-54.

Vanitha, S.C. and S. Umesha. 2008. Variations in defense related enzyme activities in tomato during the infection with bacterial wilt pathogen. J. Plant Interact. 3:245-253.

Vanitha, S.C., S.R. Niranjana, and S. Umesha. 2009. Role of phenylalanine ammonia lyase and polyphenol oxidase in host resistance to bacterial wilt of tomato. J. Phytopathol. 157:552-557.

Wang, S., Y. Li, and C. Li. 1990. A study on lily blight. Gansu Agr. Sci. Technol. 1990:30-32 (in Chinese).

Weiberg, A., M. Wang, F. Lin, H. Zhao, Z. Zhang, I. Kaloshian, H.D. Huang, and H.L. Jin. 2013. Fungal small RNAs suppress plant immunity by hijacking host RNA interference pathways. Science 342:118-123.

Yu, H., H. Zhu, L. Liu, X. Tang, and L. Wei. 2012. PAL and POD activities of soybean hypocotyls infected by Pythium. Dadou Kexue 31:495-497 (in Chinese with English abstract).

Zhang, Y., J. Gao, Q. Zhang, A. Zhang, H. Wang, and J. Sun. 2016. Research progress on plant superoxide dismutase. Anim. Husb. Feed Sci. 37:28-31 (in Chinese with English abstract).

Zhao, C., A. Wang, Y. Shi, L. Wang, W. Liu, Z. Wang, and G. Lu. 2008. Identification of defense-related genes in rice responding to challenge by Rhizoctonia solani. Theor. Appl. Genet. 116:501-516.

Zhou, B. 2012. Correlation between resistance of eggplant and defense-related enzymes and biochemical substances of leaves. Afr. J. Biotechnol. 11:13896-13902.

Zhu, L., F. Hu, and F. Luo. 2010. Identification of disease resistance of Lilium species to gray mould. Plant Protection 36:148-151 (in Chinese with English abstract). 
Supplemental Table 1. Differences between superoxide dismutase (SOD) activity on specified days after Botrytis elliptica inoculation and before inoculation (control) in seven Lilium oriental cultivars.

\begin{tabular}{|c|c|c|c|c|}
\hline Cultivar & Day 3 control & Day 5 control & Day 7 control & Day 9 control \\
\hline Constanta & $146.077 \mathrm{a}^{\mathrm{z}}$ & $37.316 \mathrm{e}$ & $39.166 \mathrm{c}$ & $34.753 \mathrm{c}$ \\
\hline Siberia & $141.472 \mathrm{a}$ & $220.249 \mathrm{a}$ & $194.495 \mathrm{a}$ & $126.942 \mathrm{a}$ \\
\hline Sorbonne & $103.876 \mathrm{~b}$ & $178.532 \mathrm{~b}$ & $56.062 \mathrm{bc}$ & $49.301 \mathrm{c}$ \\
\hline Marco Polo & $7.149 \mathrm{~d}$ & $46.325 \mathrm{de}$ & $82.487 \mathrm{~b}$ & $42.136 \mathrm{c}$ \\
\hline Francia & $17.684 \mathrm{~d}$ & $107.469 \mathrm{c}$ & $77.409 \mathrm{~b}$ & $82.973 \mathrm{~b}$ \\
\hline Rodina & $-9.2 \mathrm{~d}$ & $90.779 \mathrm{~cd}$ & $43.066 \mathrm{c}$ & $-3.327 \mathrm{~d}$ \\
\hline
\end{tabular}

${ }_{\mathrm{z}}$ Data are presented as the difference between the mean enzyme activity value at the detection time minus that before $B$. elliptica inoculation, and a different letter or letter combination indicates a significant difference at the 0.01 level between different cultivars on the same inoculation day, according to Duncan's multiple range test.

Supplemental Table 2. Differences between peroxidase (POD) activity on specified days after Botrytis elliptica inoculation and before inoculation (control) in seven Lilium oriental cultivars.

\begin{tabular}{|c|c|c|c|c|}
\hline Cultivar & Day 3 control & Day 5 control & Day 7 control & Day 9 control \\
\hline Constanta & $1.365 \mathrm{~b}^{\mathrm{z}}$ & $3.271 \mathrm{~b}$ & $2.710 \mathrm{~b}$ & $12.862 \mathrm{~b}$ \\
\hline Siberia & $4.927 \mathrm{a}$ & $7.750 \mathrm{a}$ & $5.201 \mathrm{~b}$ & $8.908 \mathrm{bc}$ \\
\hline Sorbonne & $5.591 \mathrm{a}$ & $2.085 \mathrm{~b}$ & $5.005 \mathrm{~b}$ & $7.181 \mathrm{c}$ \\
\hline Marco Polo & $1.756 \mathrm{~b}$ & $3.841 \mathrm{~b}$ & $5.933 \mathrm{~b}$ & $17.969 \mathrm{a}$ \\
\hline Francia & $1.031 \mathrm{~b}$ & $3.515 \mathrm{~b}$ & $7.153 \mathrm{~b}$ & $21.017 \mathrm{a}$ \\
\hline Rodina & $1.587 \mathrm{~b}$ & $1.559 \mathrm{~b}$ & $1.873 \mathrm{c}$ & $7.388 \mathrm{c}$ \\
\hline
\end{tabular}

${ }^{\mathrm{z}}$ Data are presented as the difference between the mean enzyme activity value at the detection time minus that before $B$. elliptica inoculation, and a different letter or letter combination indicates a significant difference at the 0.01 level between different cultivars on the same inoculation day, according to Duncan's multiple range test.

Supplemental Table 3. Differences between catalase (CAT) activity on specified days after Botrytis elliptica inoculation and before inoculation (control) in seven Lilium oriental cultivars.

\begin{tabular}{|c|c|c|c|c|}
\hline Cultivar & Day 3 control & Day 5 control & Day 7 control & Day 9 control \\
\hline Constanta & $0.458 \mathrm{~b}^{\mathrm{z}}$ & $-0.124 \mathrm{c}$ & $-0.542 \mathrm{c}$ & $-1.124 \mathrm{~d}$ \\
\hline Siberia & $0.104 \mathrm{~d}$ & $-0.23 \mathrm{~d}$ & $-0.73 \mathrm{c}$ & $-0.812 \mathrm{c}$ \\
\hline Sorbonne & $1.084 \mathrm{a}$ & $0.751 \mathrm{a}$ & $0.084 \mathrm{a}$ & $-0.167 \mathrm{a}$ \\
\hline Marco Polo & $0.208 \mathrm{~cd}$ & $0.457 \mathrm{ab}$ & $-0.292 b$ & $-0.667 \mathrm{~b}$ \\
\hline Francia & $0.124 d$ & $0.249 \mathrm{~b}$ & $0 \mathrm{ab}$ & $0 \mathrm{a}$ \\
\hline Rodina & $0.292 \mathrm{c}$ & $0.417 \mathrm{~b}$ & $0.043 \mathrm{ab}$ & $-0.041 \mathrm{a}$ \\
\hline
\end{tabular}

$\overline{\mathrm{z}}$ Data are presented as the difference between the mean enzyme activity value at the detection time minus that before $B$. elliptica inoculation, and a different letter or letter combination indicates a significant difference at the 0.01 level between different cultivars on the same inoculation day, according to Duncan's multiple range test.

Supplemental Table 4. Differences between phenylalanine ammonia-lyase (PAL) activity on specified days after Botrytis elliptica inoculation and before inoculation (control) in seven Lilium oriental cultivars.

\begin{tabular}{lcccc}
\hline Cultivar & Day 3 control & Day 5 control & Day 7 control & Day 9 control \\
\hline Constanta & $12.695 \mathrm{a}^{\mathrm{z}}$ & $12.222 \mathrm{a}$ & $14.500 \mathrm{a}$ & $4.972 \mathrm{a}$ \\
Siberia & $-6.750 \mathrm{bc}$ & $-3.139 \mathrm{bc}$ & $0.556 \mathrm{bc}$ & $1.417 \mathrm{ab}$ \\
Sorbonne & $0.889 \mathrm{~b}$ & $-4.389 \mathrm{bc}$ & $-10.361 \mathrm{~d}$ & $0.889 \mathrm{ab}$ \\
Tiber & $1.444 \mathrm{~b}$ & $-7.750 \mathrm{c}$ & $8.694 \mathrm{ab}$ & $8.333 \mathrm{a}$ \\
Marco Polo & $0.694 \mathrm{~b}$ & $11.500 \mathrm{a}$ & $-3.306 \mathrm{~cd}$ & $6.638 \mathrm{a}$ \\
Francia & $4.583 \mathrm{ab}$ & $0.750 \mathrm{~b}$ & $-2.889 \mathrm{c}$ & $-6.000 \mathrm{~b}$ \\
Rodina & $-13.778 \mathrm{c}$ & $-8.389 \mathrm{c}$ & $5.805 \mathrm{~b}$ & $6.083 \mathrm{a}$ \\
\hline
\end{tabular}

${ }^{\mathrm{z}}$ Data are presented as the difference between the mean enzyme activity value at the detection time minus that before $B$. elliptica inoculation, and a different letter or letter combination indicates a significant difference at the 0.01 level between different cultivars on the same inoculation day, according to Duncan's multiple range test. 